\title{
Physicochemical Properties and Field Evaluation of Monolithic Wax Formulations for the Controlled Release of a Forest Pest Pheromone
}

\author{
Mariel P. Slodowicz, ${ }^{*, a}$ Esteban Ceriani-Nakamurakare, ${ }^{b}$ Cecilia Carmarán $^{b}$ and \\ Paola A. González-Audino ${ }^{a, c}$
}

\author{
${ }^{a}$ Centro de Investigaciones de Plagas e Insecticidas, J. B. De La Salle 4397, \\ B1603ALO Villa Martelli, Provincia de Buenos Aires, Argentina \\ ${ }^{b}$ Departamento de Biodiversidad y Biología Experimental, FCEN, Universidad de Buenos Aires, \\ Ciudad Universitaria, Pabellón II, C1428EHA Buenos Aires, Argentina
}

\author{
'3IA, Universidad Nacional de General San Martín, Av. 25 de Mayo y Francia, San Martín, \\ Provincia de Buenos Aires, Argentina
}

\begin{abstract}
This work shows the way to develop a monolithic device for the release of an active agent. Different waxes to prepare monolithic dispensers were used. Studies to characterize the release rate of the pheromone dispensers, and to determine many physicochemical properties of the active components and waxes utilized as matrices, were conducted. The advantages of using monolithic devices as an insect pheromone dispenser in order to control an insect that attacks commercial poplar plantations were demonstrated. Also, the practical application employing monolithic dispensers manufactured in this paper with the sex pheromone of the ambrosia beetle Megaplatypus mutatus (Coleoptera: Platypodidae) was verified. This forest pest is known to attack tree plantations in South America. The release rates were mainly dependent of matrix hardness and viscosity, as well as the particle size of fillers. A good performance of the formulated monolithic dispensers was observed during the field trials, with a reduction of damage levels of $40 \%$.
\end{abstract}

Keywords: monolithic dispenser, controlled-release, sulcatone, sulcatol, 3-pentanol

\section{Introduction}

Monolithic systems are devices used for controlling the release of an active agent. ${ }^{1}$ Many factors are responsible for a solute release, such as solute concentration, diffusion coefficients of the solute, the solubility of the solute in the matrix, and other additional factors like filler materials. Physical properties of polymers and its handling characteristics can be modified by incorporation of filler materials. $^{2}$

For the analysis of controlled release data from polymeric devices of varying geometry, Ritger and Peppas ${ }^{3}$ proposed a new empirical exponential expression which relates the fractional release of drug, $\mathrm{M}_{\mathrm{t}}$ (amount released at time) $/ \mathrm{M}_{\infty}$ (amount released at time, infinity), to the release time, t. The relationship between diffusional exponent $\mathrm{n}$ and the corresponding release mechanism is clearly dependent upon the geometry

*e-mail: mariels777@gmail.com employed (like thin film, cylindrical and spherical sample).

Pheromones can be incorporated in a solid matrix to form monolithic dispensers. Because of the various materials that can be used to constitute a matrix, the release rate for a single molecule can differ significantly from one device to another. Knowledge and study of release kinetics and factors that affect pheromones release plays a crucial role in the development of efficient pheromone dispensers, giving a rational delivery of pheromones in the field. ${ }^{4}$

Pheromones are behavior-modifying semiochemicals released by insects to communicate between members of the same species. Synthetic pheromones are widely used because their species specificity and environmental profile makes them attractive for integrated pest management. ${ }^{5}$ Mating disruption strategies are part of an integrated pest management program targeting a specific pest. A key element in successful mating disruption is to create a large number of point sources emitting pheromones, thereby creating many false trails that camouflage the location of a calling insect or results in a delay in mating. ${ }^{6}$ 
Megaplatypus mutatus (Coleoptera: Platypodidae) is a South American ambrosia beetle. It attacks only standing live trees, causing severe stem breakage and death in commercial poplar (Populus) plantations. ${ }^{7}$ Also, M. mutatus was reported in plantations of brazilwood in Northeastearn Brazil. $^{8}$

In our lab, Funes et al. ${ }^{9}$ manufactured plastic pheromone reservoir dispensers for the pheromone components of M. mutatus (+)-sulcatol, sulcatone and 3-pentanol. Zero order kinetics (releasing between 60-100 mg per day of pheromone) was achieved using polyethylene bags and glass vials with semi permeable caps and successful results in M. mutatus mating disruption strategies were obtained. The (+) enantiomer of sulcatol is the natural pheromone component of the beetle. Racemic (and low cost) sulcatol can be used in replacement of (+)-sulcatol, as demonstrated in previous works that the (-) isomer does not interfere with its attracting capacity, allowing the use of racemic sulcatol both for laboratory and field tests.

In this work, monolithic dispensers for the three components known to constitute the pheromone of M. mutatus: 6-methyl-5-hepten-2-one (sulcatone), (+)-6-methyl-5-hepten-2-ol (sulcatol) and 3-pentanol were developed. Additionally, the release kinetic of these three compounds and the most important parameters that influence the release rate from these dispensers were studied. Finally, selected dispensers were deployed in field plots and its potential for the mating disruption of the beetle was evaluated.

\section{Experimental}

\section{Chemicals}

Sulcatone (6-methyl-5-hepten-2-one), $( \pm$ )-sulcatol (6-methyl-5-hepten-2-ol), from Vigon International, East Stroudsburg, PA, USA and 3-pentanol (Sigma-Aldrich, Germany) were the pheromone components utilized in the development of dispensers.

Paraffin wax of melting point (mp) $53-57$ and $70-80{ }^{\circ} \mathrm{C}$ (Sigma Aldrich, Germany), paraffin oil (Fluka, Germany), lanolin wax, bees wax, polyethylene glycol 6000 and 4000 (Parafarm S.A., Argentina), pentaerythritol ester of lanolin (Rolex Lanolin Limited, Mumbai, India, free sample), carnauba wax of Brazilian origin and stearin (Serain Juarez S.A., Buenos Aires, Argentina) were the waxes formulated into monolithic dispensers.

Glass spheres, Chinese talc (local supplier), activated charcoal (Merck, Germany), and molecular sieve of $5 \AA$ porosity and 4-8 mesh (Aldrich Chemical Company, Milwaukee, WI, USA) were the fillers added to the different matrices to alter pheromone release rates.

\section{Monolithic dispensers and release rate determination}

The pheromone is homogeneously dissolved and/or dispersed in a polymer matrix in monolithic systems. ${ }^{10}$ Preparation of dispensers for release rate studies were carried out by melting the wax matrix and by the addition of $20 \%(\mathrm{~m} / \mathrm{m})$ of the individual pheromone. The system was completely mixed and the resulting mixture was poured into a mold with half sphere shaped wells of $3 \mathrm{~cm}$ diameter. Molded dispensers were solidified in the fridge. Dispensers were removed from the mold for evaluation in wind tunnel at $29-30{ }^{\circ} \mathrm{C}$ with a wind speed of $0.5-0.6 \mathrm{~m} \mathrm{~s}^{-1}$. The devices were placed inside the tunnel and the pheromone components mass loss quantified during 30-70 days until their release rate were less than $10 \mathrm{mg}$ per day. Three replicates were performed for each release rate experiment. The devices were developed using $20 \% \mathrm{~m} / \mathrm{m}$ pheromone component for all cases because it was observed in previous studies in our laboratory that, with this amount of pheromone component, the device releases sufficient quantities of active agent and has a good texture without matrices ruptures. Furthermore, good results were observed in the field using this concentration of active ingredient. ${ }^{11}$

Graphs of pheromone components release from dispensers were plotted using SigmaPlot 11.0 software, by plotting the residual mass in the dispensers versus time in days. Release rates were determined by differentiation of the curve mass vs. time using Origin 6.0 software.

\section{Waxes solubility}

Wax solubility was measured in toluene and 2-propanol. Measuring solubility in water was not possible because most waxes have low solubility in this polar solvent. Since the polarities of the two solvents are very different, we calculated a quotient between the two solubilities, S, for each matrix, obtaining the parameter $S_{\text {toluene }} / S_{2 \text {-propanol }}$. Solubility measurements were made in test tubes. A small amount of the wax or mix of waxes (10-30 mg) was weighed, and a continuous process of addition of solventheating-cooling followed until complete dissolution of the wax. Complete solubilization was considered when no turbidity was noticed after 5 hours at $23{ }^{\circ} \mathrm{C}$. Matrix solubility was determined in both solvents by three replicates.

\section{Dispersion ability of pheromone components in matrices}

For the determination of pheromone components dispersion ability in matrices, a small amount of wax or 
mix of waxes (10-30 mg) was weighed in an assay tube. Then, a known volume of the pheromone component was added, and the mixture was heated until homogenization; afterwards, the system was allowed to reach room temperature until complete solidification. The addition of the pheromone component continued until the appearance of a heterogeneous (pheromone component liquid phase) phase of pheromone component (maximum dispersion of pheromone in the matrix). As a result, in all experiments solid solutions were formed until the dispersion value limit of pheromone component in the matrices was reached. Pheromone component dispersion in matrices was determined in three replicates.

\section{Matrices and pheromone components viscosity}

Kinematic viscosity of pheromone components and wax matrices was measured (in centiStokes) at 20 and $100{ }^{\circ} \mathrm{C}$, respectively. Kinematic viscosity of solid substances was measured away from the melting point because near that temperature, solids would not behave as a Newtonian fluid. The analyses were made following ASTM D445-06 method $^{12}$ modified in sections 6.3 and 6.4 of the norm by applying \pm 0.1 instead of $\pm 0.02{ }^{\circ} \mathrm{C}$.

Polarity $(\log P)$ and molecular volume of pheromone components

Pheromone components molecules were built using Molecular Modelling software (HyperChem Release software 8.0, Hypercube, INC), drawn with 3D Model Builder, the double bonds were marked and the structure was minimized using the $\mathrm{MM}^{+}$force field. Polarity, as $\log \mathrm{P}$, and molecular volume were calculated with HyperChem 8.0 software using the QSAR-properties menu.

\section{Melting point of waxes}

Melting point ( $\mathrm{mp}$ ) was measured in a fusiometer model 7911 ISV brand equipped with a glycerin bath, where a capillary tube containing the wax sample was heated up to the fusion temperature of the wax.

\section{Filler particle and pore size}

Filler particle size by scanning electron microscopy (SEM) by taking images at different magnifications $(\times 50, \times 200$, $\times 1000$ and $\times 4000)$ was determined. The filler samples were mounted on a stub of metal with adhesive coated with $60-40 \mathrm{~nm}$ of gold. Particles were treated as ellipses for surface determination. We sampled 40 particles per picture and calculated a weighed mean surface. In the same way, the pore size for activated charcoal, one of the porous filler, was calculated.

\section{Shore D hardness}

The matrices hardness assay was performed with a $\mathrm{S} 1$ N122608 Shore D hardness tester by the ASTM D 2240 method. ${ }^{13}$ The conditions during this assay were maintained at $23{ }^{\circ} \mathrm{C}$, with a $50 \%$ of relative humidity. Twelve replicates per sample of matrix were carried out in the experiments.

Statistical analysis of physicochemical parameters and pheromone components release rates

Statistical analysis was performed using InfoStat software (National University of Córdoba, Argentina). Normality assumption with Shapiro-Wilk test was studied. The regressions with the better adjustments of data were selected taking into account the lowest values of standard error, Akaike information criterion (AIC) and Bayesian information criterion (BIC).

\section{Field evaluations trials}

Field trials were performed during the flight season of M. mutatus between 15 February and 24 April 2013, in a 12 ha stand of 12 year-old Populus deltoides tree plantation located at Alberti, Buenos Aires Province, Argentina, with a diameter at breast height (DBH) of $78.5 \pm 0.47 \mathrm{~cm}$. From the 12 ha stand, three 0.5 ha areas were delimited; two areas for treatment and one for control; each area was separated by $150 \mathrm{~m}$. The pheromone dispensers were pinned on a small nail on the surface of the trees in sets of three (one dispenser for each pheromone component) adjacent to each other, at $1.6 \mathrm{~m}$ above the ground. The sets were uniformly distributed throughout each treatment plot at a density of 40 sets of three per ha. Devices were checked weekly and replaced before total depletion. Two parameters were used to evaluate damage by $M$. mutatus: mating galleries $(\mathrm{MG})$ and active galleries $(\mathrm{AG}){ }^{14,15}$ M. mutatus damage in control and pheromone-treated plots was assessed before placing the pheromone devices and 21 days after treatment. Damage assessment was carefully carried out before the trial by examining tree trunks, identifying $\mathrm{AG}$ and $\mathrm{MG}$, and numbering them individually. In both treated and control plots, we randomly sampled 14 trees $\mathrm{ha}^{-1}$. Damage in treated and control plots was expressed as mean number of MG or AG per tree, and was compared by a $t$-test after the trial (Statistica 5.0; StatSoft, Tulsa, OK, USA). 


\section{Results and Discussion}

\section{Physicochemical properties of matrices}

Table 1 shows the obtained values for solubility in toluene and 2-propanol, and the $\mathrm{S}_{\text {toluene }} / \mathrm{S}_{2 \text {-propanol }}$ coefficients for wax matrices. Table 2 presents the melting points, Shore D hardness and kinematic viscosities of the matrices. Lanolin wax and polyethylene glycols 4000 and 6000 showed the highest values of $\mathrm{S}_{\text {toluene }} / \mathrm{S}_{2 \text {-propanol }}$ coefficients while stearin showed the lowest value. In the case of polyethylene glycols matrices, higher values of $\mathrm{S}_{\text {toluene }} / \mathrm{S}_{2 \text {-propanol }}$ quotient are probably due to its amphiphilic property $^{16}$ and to the formation of enriched phases of polymer in these polyethylene glycols matrices thanks to the presence of hydrophobic groups of methylene along polymer chain that are inserted between the alcohol or ether groups ${ }^{17}$ (Table 1). The results also showed that the harder matrices were polyethylene glycol 4000 and 6000 and carnauba wax, while the softer matrices were paraffin wax mp $53-57^{\circ} \mathrm{C}$ and stearin. Hardness of lanolin wax, pentaerythritol ester of lanolin and paraffin wax mp $53-57{ }^{\circ} \mathrm{C}(40 \%)+$ paraffin oil $(60 \%)$ could not be determined with this method because they were not hard enough for their measurement (Table 2).

Polyethylene glycol 6000 and 4000 showed the highest kinematic viscosities values, while paraffin wax $m p 53-57^{\circ} \mathrm{C}$ and paraffin oil/paraffin wax mp $53-57^{\circ} \mathrm{C}$ showed the lowest viscosity values measured at $100{ }^{\circ} \mathrm{C}$ (Table 2).

$\mathrm{Kung}^{18}$ in 1997 found that for cellulose acetate butyrate solution used for microencapsulation, drug loading was significantly influenced by the solution viscosity, where higher viscosity of the polymer solution produced microcapsules with low drug loading.

Regarding to the three pheromone components, sulcatone presented the lowest viscosity and sulcatol, the

Table 1. Values of solubility in toluene and 2-propanol, and $\mathrm{S}_{\text {toluene }} / \mathrm{S}_{2 \text {-propanol }}$ coefficients for wax matrices

\begin{tabular}{|c|c|c|c|}
\hline Matrix & $\begin{array}{l}\text { Solubility in toluene } \pm \mathrm{SE}^{\mathrm{a}, \mathrm{b}} / \\
\quad(\mathrm{g} \text { per } 100 \mathrm{~mL})\end{array}$ & $\begin{array}{l}\text { Solubility in 2-propanol } \pm \mathrm{SE}^{\mathrm{a}, \mathrm{b}} / \\
\quad(\mathrm{g} \text { per } 100 \mathrm{~mL})\end{array}$ & $\mathrm{S}_{\text {toluene }} / \mathrm{S}_{2 \text {-propanol }}$ \\
\hline Paraffin wax mp $70-80^{\circ} \mathrm{C}$ & $0.269 \pm 0.008$ & $0.0073 \pm 0.0003$ & 37 \\
\hline Paraffin wax mp $53-57^{\circ} \mathrm{C}$ & $1.585 \pm 0.113$ & $0.0170 \pm 0.0005$ & 93 \\
\hline Paraffin wax mp $53-57^{\circ} \mathrm{C}+$ paraffin oil & $4.101 \pm 0.116$ & $0.0458 \pm 0.0026$ & 90 \\
\hline Lanolin pentaerythritol ester & $26.786 \pm 1.273$ & $0.0377 \pm 0.0019$ & 711 \\
\hline Stearin & $13.863 \pm 0.615$ & $4.693 \pm 0.234$ & 3 \\
\hline Carnauba wax & $2.219 \pm 0.218$ & $0.0056 \pm 0.0002$ & 396 \\
\hline Bees wax & $6.670 \pm 0.589$ & $0.0116 \pm 0.0002$ & 575 \\
\hline Lanolin wax & $69.850 \pm 5.211$ & $0.1583 \pm 0.0001$ & 441 \\
\hline Polyethylene glycol 4000 & $6.706 \pm 0.236$ & $0.0057 \pm 0.0001$ & 1176 \\
\hline Polyethylene glycol 6000 & $6.083 \pm 0.219$ & $0.0045 \pm 0.0002$ & 1352 \\
\hline
\end{tabular}

${ }^{\text {aSE: }}$ standard error $=$ standard deviation/(replicas numbers ${ }^{0.5}$; bafter 5 hours at room temperature.

Table 2. Melting points, Shore D hardness and kinematic viscosities values of wax matrices

\begin{tabular}{|c|c|c|c|}
\hline Matrix & Melting point $/{ }^{\circ} \mathrm{C}$ & Kinematic viscosity / cSt & Shore D hardness ${ }^{\mathrm{b}} \pm \mathrm{SE}$ \\
\hline Paraffin wax mp $70-80{ }^{\circ} \mathrm{C}$ & 75.0 & 9.2 & $70.9 \pm 4.3$ \\
\hline Paraffin wax mp $53-57{ }^{\circ} \mathrm{C}$ & 55.0 & 4.1 & $64.0 \pm 5.6$ \\
\hline Paraffin wax mp $53-57^{\circ} \mathrm{C}+$ paraffin oil & 42.3 & 5.4 & $-^{c}$ \\
\hline Lanolin pentaerythritol ester & 52.5 & - & $-^{c}$ \\
\hline Stearin & 57.0 & 5.5 & $64.5 \pm 4.2$ \\
\hline Carnauba wax & 80.5 & 37.0 & $81.9 \pm 7.9$ \\
\hline Bees wax & 61.7 & 11.0 & $71.0 \pm 4.0$ \\
\hline Lanolin wax & 32.0 & 35.4 & $-^{\mathrm{c}}$ \\
\hline Polyethylene glycol 4000 & 51.3 & 135.3 & $83.6 \pm 8.0$ \\
\hline Polyethylene glycol 6000 & 53.0 & 340.6 & $86.7 \pm 8.0$ \\
\hline
\end{tabular}

${ }^{\mathrm{a}}$ Waxes kinematic viscosities measured at $100{ }^{\circ} \mathrm{C} ;{ }^{\mathrm{b}} \mathrm{SE}=$ standard error; SE $=$ standard deviation/(replicas numbers $)^{0.5}$; ${ }^{\mathrm{c}} \mathrm{could}$ not be determined because these matrices were too soft to perform the hardness analysis. 
Table 3. $\log$ P, kinematic viscosity (measured at $20^{\circ} \mathrm{C}$ ) and molecular volume of pheromone components

\begin{tabular}{lccc}
\hline Pheromone component & Kinematic viscosity / cSt & $\log \mathrm{P}$ & ${\text { Molecular volume / } \AA^{3}}^{\text {Sulcatone }}$ \\
3-Pentanol & 1.148 & 2.09 & 524.45 \\
Sulcatol & 7.472 & 1.43 & 390.32 \\
\hline
\end{tabular}

highest, measured at $20^{\circ} \mathrm{C}$. 3-Pentanol had the lowest $\log \mathrm{P}$ as it is the more polar molecule, and sulcatone, the highest $\log \mathrm{P}$ value as it is the less polar molecule (Table 3 ).

The dispersion values of the pheromone components are presented in Figure 1. The results indicated that 3-pentanol had the highest ability to disperse in paraffin wax mp 53$57^{\circ} \mathrm{C}$, followed by paraffin wax mp $70-80^{\circ} \mathrm{C}$, paraffin oil mixed with paraffin wax mp $53-57^{\circ} \mathrm{C}$, carnauba wax, pentaerythritol ester of lanolin and lanolin wax (possibly due to the smaller sized molecule that would be better accommodated in the structure of the waxes) but had low dispersion values in stearin and bees wax. Sulcatone had the highest ability to disperse in stearin and lower dispersion values in the other matrices. Sulcatol had the highest ability to disperse in bees wax and lower values in the other matrices. Also, higher values of dispersion ability of pheromone components would allow preparation of dispensers with a more amount of active agent (pheromone). Generally, the active agent dissolves in the polymeric or elastomeric matrix until saturation. Additional active agent remains dispersed within the polymer matrix after it is physically dispersed and molded or cured. As the agent evaporates from the surface of the monolithic device, more agent diffuses out from the interior in response to the decreased concentration gradient leading to the surface. ${ }^{1}$ The diffusion of pheromone components in matrices affects the release rates of active compounds in the monolithic dispensers.

Filler material surface and pore size were obtained from SEM. Larger size fillers, such as molecular sieve and glass spheres, were measured with a caliber ( $\pm 0.5 \mathrm{~mm}$ error). In the case of molecular sieve and activated charcoal, which are porous materials, surface was determined from pore size (Table 4).

Particle surface of filler types ordered from smallest to largest was kaolin, Chinese talc, activated charcoal, glass spheres and molecular sieve.

There can be a large increase in solubility of molecular species that strongly interact with the surfaces of inorganic fillers. The presence of filler particles can also affect the diffusion behavior. Filler particles lead to the presence of internal interfaces within the material that may play a role in the diffusion process. Conversely, strong interactions between diffusing molecules and particle surfaces may reduce permeation rates. ${ }^{18}$

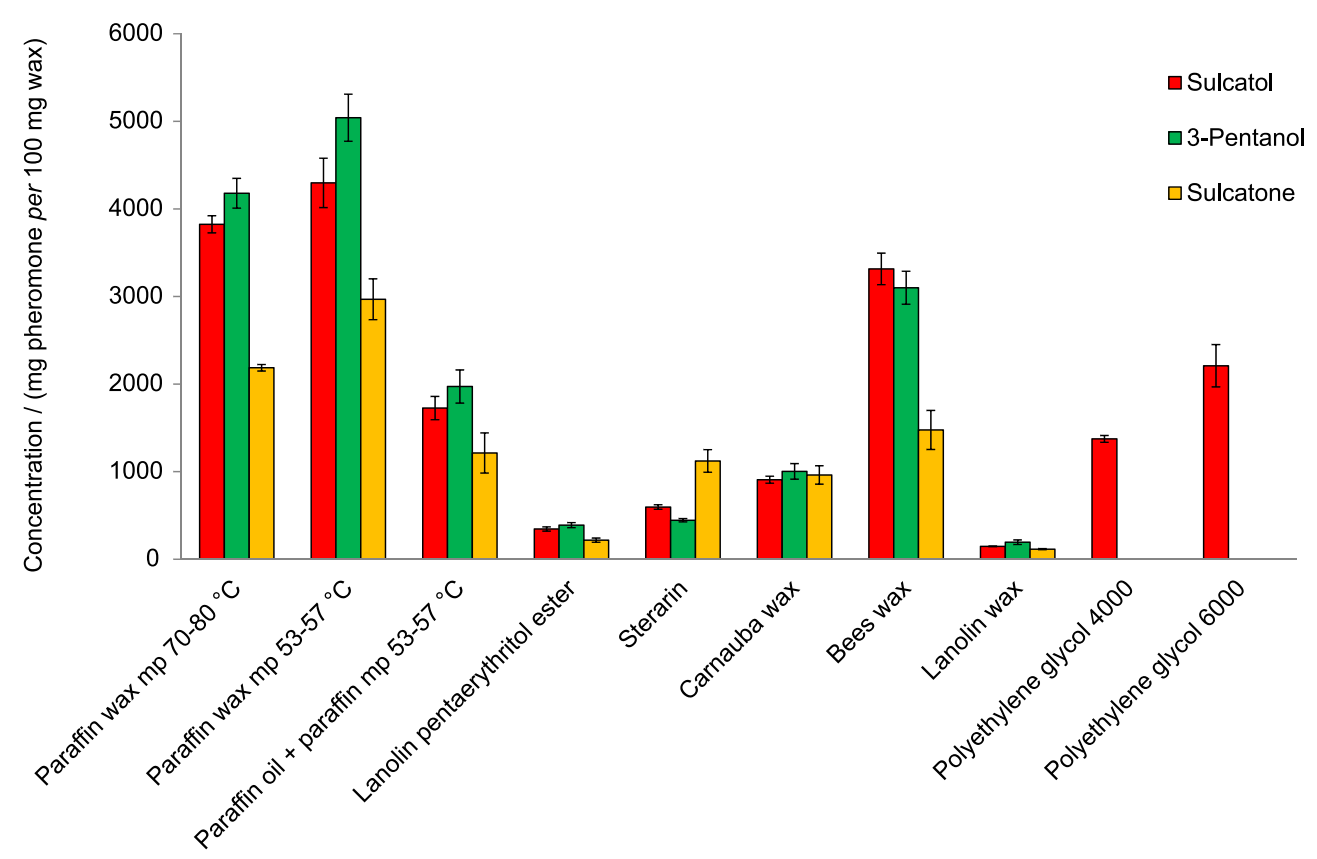

Figure 1. Dispersion values of pheromone components of M. mutatus in matrices. 
Table 4. Filler materials surfaces determinations

\begin{tabular}{lcc}
\hline Filler material & Particle surface (weighted average) $/ \mu \mathrm{m}^{2}$ & Pore size $($ weighted average $) / \mu \mathrm{m}^{2}$ \\
\hline Micronized kaolin & 59 & - \\
Activated charcoal & 14250 & 46 \\
Chinese talc & 711 & - \\
Molecular sieves & 40571118 & $1.96 \times 10^{-6}$ \\
Glass spheres & 2269800 & - \\
\hline
\end{tabular}

\section{Pheromone components release rates}

The equation of depletion of pheromone components from wax formulations was characterized by $\mathrm{m}=\mathrm{ct}^{1 / 2}$, where $\mathrm{m}$ is the daily cumulative mass, $\mathrm{c}$ is a constant and $\mathrm{t}$ is the time in days. The $p$-value (probability) was $<0.0001$ in all determinations, and means significant difference for c parameter in the regression expression. This equation describes a solute release when it is dispersed in a matrix. ${ }^{2}$

The initial release rates $V_{i}$ were calculated from the release rates curves, and the time $t$ was measured in days until the release rate of the pheromone components was less than $10 \mathrm{mg}$ per day (Tables 5, 6 and 7).

The release rates obtained in these experiments were in the 4-400 mg per day range, approximately.

For sulcatone, the results showed that the highest $\mathrm{V}_{\mathrm{i}} \mathrm{s}$ were obtained with pentaerythritol ester of lanolin $+20 \% \mathrm{~m} / \mathrm{m}$ kaolin and with carnauba wax $+20 \% \mathrm{~m} / \mathrm{m}$ glass spheres releasing over $400 \mathrm{mg}$ of sulcatone in the initial day. The lowest $\mathrm{V}_{\mathrm{i}} \mathrm{s}$ were obtained with stearin and stearin mixed with $20 \%$ kaolin, releasing 27.3 and $33.7 \mathrm{mg}$ in the initial day, respectively (Table 5). In almost all matrices where kaolin was used as filler material in concentrations of 10 , 20 and $30 \% \mathrm{~m} / \mathrm{m}, \mathrm{V}_{\mathrm{i}}$ increased in the order $\mathrm{V}_{\mathrm{i}} 10 \%, \mathrm{~V}_{\mathrm{i}} 20 \%$, $\mathrm{V}_{\mathrm{i}} 30 \%$ (Table 5). Knowing the $\mathrm{t}$ value, the time of depletion of dispensers for their usage in future field trials can be estimated. The longest $t$ values were noticed in paraffin $\mathrm{mp} 53-57^{\circ} \mathrm{C}+20 \% \mathrm{~m} / \mathrm{m}$ Chinese talc and in stearin $+20 \%$ Chinese talc matrices; the shortest $t$ values were obtained in bees wax and stearin matrices.

For 3-pentanol, the results demonstrated that the highest $\mathrm{V}_{\mathrm{i}} \mathrm{s}$ were obtained with carnauba wax $+20 \% \mathrm{~m} / \mathrm{m}$ molecular sieve, releasing over $500 \mathrm{mg}$ of 3-pentanol in the initial day. The lowest $\mathrm{V}_{\mathrm{i}} \mathrm{s}$ were obtained with stearin without fillers and with stearin mixed with $20 \%$ kaolin, releasing 21.9 and $31.6 \mathrm{mg}$ in the first day, respectively (Table 6). The longest $\mathrm{t}$ value was observed in stearin $+20 \%$ kaolin matrix and the shortest $t$ value, in stearin matrix without filler (Table 6).

For sulcatol dispensers, the highest $\mathrm{V}_{\mathrm{i}} \mathrm{s}$ were obtained in polyethylene glycol $4000+20 \% \mathrm{~m} / \mathrm{m}$ activated charcoal matrix, and the lowest $\mathrm{V}_{\mathrm{i}} \mathrm{s}$ were obtained with stearin without filler and with stearin $+20 \% \mathrm{~m} / \mathrm{m}$ Chinese talc, releasing 9.7 and $12.1 \mathrm{mg}$ in the first day, respectively (Table 7). In the cases where pheromone release rates without fillers were very low (less than $20 \mathrm{mg}$ per day) we did not try mixtures with fillers (Table 7). The longest $t$ value was observed in polyethylene glycol 6000 without filler matrix, and the shortest $\mathrm{t}$ value was obtained when stearin without filler matrix was employed. In cases where the initial release rates of the pheromone compounds without filler were very low for sulcatol (less than $30 \mathrm{mg}$ per day) or matrices were very soft for handling or field use (lanolin wax, paraffin oil/paraffin $\mathrm{mp} 53-57^{\circ} \mathrm{C}$ ), the respective mixtures with fillers were not tested.

For sulcatol, sulcatone and 3-pentanol, $\mathrm{V}_{\mathrm{i}}$ increases with the addition of filler materials in almost all matrices; the increment of filler concentration increases $V_{i}$ probably due to an increment of matrix tortuosity that favors a faster release of pheromone to the environment. As the particle filler surface increases, the parameter $V_{i}$ increases too. In particular, for 3-pentanol, if the filler particle size decreases, $\mathrm{V}_{\mathrm{i}}$ diminishes. Consequently, a lower amount of pheromone component from the matrix would be released over time, because a smaller filler particle size would interact more with 3-pentanol molecule.

It is important to mention here that the selection of monolithic dispensers for field trials needs to be done with a number of criteria in mind. For instance, $V_{i}$ of dispensers ought to be relatively high and constant, and release the necessary amount of pheromone component to produce the mating disruption of the insect. On the other hand, melting point and hardness of the mixtures of matrices + fillers + pheromones should be considered, as dispensers could easily melt in field conditions during warm summer temperatures or be easily washed away by heavy rains. So, the selection of the optimal dispenser with the commitment of all these factors combined together should be made.

Comparing the Vi of the three pheromone components for all matrices, with the exception of carnauba wax, $\mathrm{V}_{\mathrm{i}}$ of sulcatol, sulcatone and 3-pentanol without fillers in increasing order was: $V_{\text {isulcatol }}, V_{\text {i3-pentanol }}, V_{\text {isulcatone }}$. For carnauba wax, $\mathrm{V}_{\mathrm{i}}$ in increasing order was: $\mathrm{V}_{\text {isulcatol }}$, 
Table 5. $\mathrm{V}_{\mathrm{i}}$, c, and t parameters from release curves with their respective standard errors of wax monolithic dispensers for sulcatone

\begin{tabular}{|c|c|c|c|c|}
\hline \multicolumn{5}{|c|}{ Release rate parameters of the curve $\mathrm{m}=\mathrm{ct}^{1 / 2}$ for sulcatone $(20 \% \mathrm{~m} / \mathrm{m})$} \\
\hline Matrix & $\mathrm{c}$ & Standard error ${ }^{\mathrm{a}}$ & $\mathrm{V}_{\mathrm{i}}^{\mathrm{b}} /(\mathrm{mg}$ per day $)$ & $\mathrm{t}^{\mathrm{c} / \text { day }}$ \\
\hline Paraffin mp $53-57^{\circ} \mathrm{C}+10 \%$ kaolin & 2.820 & 0.7765 & 99.8 & 37 \\
\hline Paraffin mp $53-57^{\circ} \mathrm{C}+20 \%$ kaolin & 2.701 & 0.5573 & 140.6 & 33 \\
\hline Paraffin mp 53-57 ${ }^{\circ} \mathrm{C}+30 \%$ kaolin & 2.602 & 0.5550 & 173.8 & 33 \\
\hline Paraffin mp $53-57^{\circ} \mathrm{C}+20 \%$ glass spheres & 3.088 & 1.2742 & 102.7 & 33 \\
\hline Paraffin mp $53-57^{\circ} \mathrm{C}+20 \%$ molecular sieve & 3.125 & 1.4317 & 87.0 & 33 \\
\hline Paraffin mp $53-57^{\circ} \mathrm{C}+20 \%$ activated charcoal & 2.979 & 0.9140 & 106.3 & 33 \\
\hline Paraffin mp $53-57^{\circ} \mathrm{C}+20 \%$ Chinese talc & 1.900 & 0.6545 & 63.6 & 84 \\
\hline Paraffin mp $53-57^{\circ} \mathrm{C}$ & 2.982 & 0.7884 & 60.3 & 45 \\
\hline Paraffin oil + paraffin $\mathrm{mp} 53-57^{\circ} \mathrm{C}+10 \%$ kaolin & 2.813 & 0.6624 & 142.4 & 33 \\
\hline Paraffin oil + paraffin $\mathrm{mp} 53-57^{\circ} \mathrm{C}+20 \%$ kaolin & 2.244 & 0.7990 & 157.0 & 33 \\
\hline Paraffin oil + paraffin mp $53-57^{\circ} \mathrm{C}+30 \%$ kaolin & 2.332 & 0.5806 & 162.4 & 33 \\
\hline Paraffin oil + paraffin mp $53-57^{\circ} \mathrm{C}+20 \%$ glass spheres & 1.781 & 0.3739 & 90.1 & 33 \\
\hline Paraffin oil + paraffin mp $53-57^{\circ} \mathrm{C}+20 \%$ molecular sieve & 2.158 & 0.4711 & 119.2 & 33 \\
\hline Paraffin oil + paraffin mp $53-57^{\circ} \mathrm{C}+20 \%$ activated charcoal & 1.992 & 0.3462 & 183.5 & 33 \\
\hline Paraffin oil + paraffin mp $53-57^{\circ} \mathrm{C}$ & 1.885 & 0.8077 & 120.7 & 45 \\
\hline Paraffin mp $70-80^{\circ} \mathrm{C}+10 \%$ kaolin & 2.192 & 0.6299 & 79.5 & 33 \\
\hline Paraffin $\mathrm{mp} 70-80^{\circ} \mathrm{C}+20 \%$ kaolin & 2.086 & 0.5888 & 71.7 & 33 \\
\hline Paraffin mp $70-80{ }^{\circ} \mathrm{C}+30 \%$ kaolin & 1.478 & 0.2870 & 123.3 & 33 \\
\hline Paraffin mp $70-80{ }^{\circ} \mathrm{C}+20 \%$ glass spheres & 2.146 & 0.7732 & 56.2 & 33 \\
\hline Paraffin $\mathrm{mp} 70-80^{\circ} \mathrm{C}+20 \%$ molecular sieve & 2.294 & 0.7437 & 84.3 & 33 \\
\hline Paraffin mp $70-80{ }^{\circ} \mathrm{C}+20 \%$ activated charcoal & 2.249 & 0.5718 & 137.6 & 33 \\
\hline Paraffin mp $70-80^{\circ} \mathrm{C}$ & 3.026 & 0.9028 & 70.8 & 29 \\
\hline Pentaerythritol ester of lanolin $+20 \%$ kaolin & 1.160 & 0.3576 & 449.2 & 33 \\
\hline Pentaerythritol ester of lanolin & 1.807 & 1.1369 & 241.3 & 45 \\
\hline Lanolin wax $+20 \%$ kaolin & 0.778 & 0.5579 & 325.0 & 43 \\
\hline Lanolin wax & 1.080 & 0.5629 & 333.3 & 29 \\
\hline Carnauba wax $+10 \%$ kaolin & 1.615 & 0.3340 & 61.9 & 54 \\
\hline Carnauba wax $+20 \%$ kaolin & 2.252 & 0.5476 & 61.7 & 57 \\
\hline Carnauba wax $+30 \%$ kaolin & 2.812 & 0.7184 & 77.1 & 57 \\
\hline Carnauba wax $+20 \%$ glass spheres & 0.584 & 0.6137 & 410.1 & 26 \\
\hline Carnauba wax $+20 \%$ molecular sieve & 2.063 & 0.5491 & 138.9 & 29 \\
\hline Carnauba wax $+20 \%$ activated charcoal & 1.923 & 0.4356 & 92.3 & 52 \\
\hline Carnauba wax & 1.207 & 0.9665 & 269.4 & 41 \\
\hline Bees wax & 2.231 & 0.5972 & 95.0 & 25 \\
\hline Bees wax $+20 \%$ kaolin & 1.789 & 0.4072 & 226.8 & 57 \\
\hline Bees wax $+20 \%$ Chinese talc & 2.563 & 0.7498 & 240.9 & 58 \\
\hline Stearin & 1.986 & 0.6296 & 27.3 & 20 \\
\hline Stearin $+20 \%$ kaolin & 4.905 & 4.5094 & 33.7 & 66 \\
\hline Stearin $+20 \%$ Chinese talc & 5.395 & 5.2566 & 43.1 & 80 \\
\hline
\end{tabular}

a Standard error obtained from SigmaPlot software; ${ }^{\mathrm{b}}$ calculated from the differentiation of the pheromone component release curve mass $v s$. time; ${ }^{\mathrm{c}}$ time in days until the release rate of the pheromone component was less than $10 \mathrm{mg}$ per day.

$\mathrm{V}_{\text {isulcatone }}, \mathrm{V}_{\text {i3-pentanol }}$. For all the paraffin waxes, including pentaerythritol ester of lanolin, lanolin wax, stearin and bees wax matrices, $\mathrm{V}_{\mathrm{i}}$ without fillers were compared. Then, it was noticed that $\mathrm{V}_{\mathrm{i} \text {-pentanol }}$, the most polar molecule, was the smallest, and $\mathrm{V}_{\text {isulcatone, }}$, the least polar molecule, was the highest. Carnauba wax presented different $\mathrm{V}_{\mathrm{i}} \mathrm{s}$ for the three pheromone components, where sulcatol had the lowest $\mathrm{V}_{\mathrm{i}}$ and 3-pentanol had the highest $\mathrm{V}_{\mathrm{i}}$ in this matrix.

The highest release rates for sulcatone compared to sulcatol and 3-pentanol could be attributed to its inability to form hydrogen bonds towards esters, thus decreasing interaction and increasing release rate.

Analysis of pheromone components transport from wax dispensers

The value of $\mathrm{n}$, the diffusion exponent, was calculated by plotting the experimental data of pheromone components 
Table 6. $\mathrm{V}_{\mathrm{i}}$, c, and t parameters from release curves with their respective standard errors of wax monolithic dispensers for 3-pentanol

\begin{tabular}{|c|c|c|c|c|}
\hline \multicolumn{5}{|c|}{ Release rate parameters of the curve $\mathrm{m}=\mathrm{ct}^{1 / 2}$ for 3 -pentanol $(20 \% \mathrm{~m} / \mathrm{m})$} \\
\hline Matrix & $\mathrm{c}$ & Standard error ${ }^{\mathrm{a}}$ & $\mathrm{V}_{\mathrm{i}}^{\mathrm{b}} /(\mathrm{mg}$ per day $)$ & $\mathrm{t}^{\mathrm{c} / \text { day }}$ \\
\hline Paraffin mp $53-57^{\circ} \mathrm{C}+10 \%$ kaolin & 2.658 & 1.1157 & 65.9 & 32 \\
\hline Paraffin mp $53-57^{\circ} \mathrm{C}+20 \%$ kaolin & 2.035 & 0.5186 & 85.7 & 32 \\
\hline Paraffin mp $53-57^{\circ} \mathrm{C}+30 \%$ kaolin & 2.127 & 0.3769 & 189.5 & 32 \\
\hline Paraffin mp $53-57^{\circ} \mathrm{C}+20 \%$ glass spheres & 3.971 & 1.5550 & 41.2 & 32 \\
\hline Paraffin mp $53-57^{\circ} \mathrm{C}+20 \%$ molecular sieve & 3.441 & 1.8681 & 55.0 & 32 \\
\hline Paraffin mp $53-57^{\circ} \mathrm{C}+20 \%$ activated charcoal & 2.817 & 1.2241 & 92.8 & 32 \\
\hline Paraffin mp $53-57^{\circ} \mathrm{C}+20 \%$ Chinese talc & 3.851 & 3.0523 & 39.4 & 55 \\
\hline Paraffin mp $53-57^{\circ} \mathrm{C}$ & 2.891 & 0.9340 & 31.9 & 37 \\
\hline Paraffin oil + paraffin mp $53-57^{\circ} \mathrm{C}+10 \%$ kaolin & 2.755 & 0.7570 & 126.1 & 61 \\
\hline Paraffin oil + paraffin mp $53-57^{\circ} \mathrm{C}+20 \%$ kaolin & 2.523 & 1.0329 & 142.4 & 61 \\
\hline Paraffin oil + paraffin $m p 53-57{ }^{\circ} \mathrm{C}+30 \%$ kaolin & 2.199 & 1.1170 & 173.9 & 57 \\
\hline Paraffin oil + paraffin mp $53-57{ }^{\circ} \mathrm{C}+20 \%$ glass spheres & 2.414 & 0.6077 & 120.2 & 57 \\
\hline Paraffin oil + paraffin mp $53-57{ }^{\circ} \mathrm{C}+20 \%$ molecular sieve & 1.958 & 0.6968 & 183.3 & 61 \\
\hline Paraffin oil + paraffin mp $53-57^{\circ} \mathrm{C}+20 \%$ activated charcoal & 1.890 & 1.0373 & 130.1 & 61 \\
\hline Paraffin oil + paraffin mp $53-57^{\circ} \mathrm{C}$ & 2.058 & 0.6988 & 74.6 & 45 \\
\hline Paraffin $\mathrm{mp} 70-80^{\circ} \mathrm{C}+10 \%$ kaolin & 2.071 & 0.8576 & 47.3 & 33 \\
\hline Paraffin $\mathrm{mp} 70-80^{\circ} \mathrm{C}+20 \%$ kaolin & 2.208 & 0.8416 & 86.8 & 33 \\
\hline Paraffin mp $70-80{ }^{\circ} \mathrm{C}+30 \%$ kaolin & 2.065 & 0.5690 & 124.8 & 33 \\
\hline Paraffin $\mathrm{mp} 70-80^{\circ} \mathrm{C}+20 \%$ glass spheres & 2.939 & 1.2982 & 74.2 & 33 \\
\hline Paraffin mp $70-80{ }^{\circ} \mathrm{C}+20 \%$ molecular sieve & 2.930 & 1.0561 & 83.2 & 33 \\
\hline Paraffin $\mathrm{mp} 70-80^{\circ} \mathrm{C}+20 \%$ activated charcoal & 3.460 & 1.5202 & 47.0 & 33 \\
\hline Paraffin mp $70-80^{\circ} \mathrm{C}$ & 3.077 & 1.0039 & 37.6 & 37 \\
\hline Pentaerythritol ester of lanolin $+20 \%$ kaolin & 1.592 & 0.7668 & 328.9 & 33 \\
\hline Pentaerythritol ester of lanolin & 1.826 & 0.9254 & 196.2 & 45 \\
\hline Lanolin wax $+20 \%$ kaolin & 1.777 & 0.6011 & 203.2 & 57 \\
\hline Lanolin wax & 1.594 & 0.7724 & 190.8 & 45 \\
\hline Carnauba wax $+10 \%$ kaolin & 0.628 & 0.5533 & 230.8 & 38 \\
\hline Carnauba wax $+20 \%$ kaolin & 1.076 & 0.6001 & 378.7 & 43 \\
\hline Carnauba wax $+30 \%$ kaolin & 1.327 & 0.8663 & 263.6 & 50 \\
\hline Carnauba wax $+20 \%$ glass spheres & 1.174 & 0.2043 & 401.5 & 38 \\
\hline Carnauba wax $+20 \%$ molecular sieve & 1.985 & 0.3359 & 538.7 & 38 \\
\hline Carnauba wax $+20 \%$ activated charcoal & 0.937 & 0.5525 & 403.7 & 38 \\
\hline Carnauba wax & 1.097 & 0.4919 & 402.9 & 29 \\
\hline Bees wax & 2.567 & 0.8584 & 50.4 & 25 \\
\hline Bees wax $+20 \%$ kaolin & 2.755 & 0.8888 & 187.7 & 64 \\
\hline Bees wax $+20 \%$ Chinese talc & 4.211 & 3.3016 & 134.2 & 66 \\
\hline Stearin & 1.896 & 0.5667 & 21.9 & 18 \\
\hline Stearin $+20 \%$ kaolin & 4.600 & 4.4004 & 31.6 & 73 \\
\hline Stearin $+20 \%$ Chinese talc & 4.502 & 3.3392 & 59.2 & 64 \\
\hline
\end{tabular}

a Standard error obtained from SigmaPlot software; bcalculated from the differentiation of the pheromone component release curve mass $v s$. time; ${ }^{\mathrm{c}}$ time in days until the release rate of the pheromone component was less than $10 \mathrm{mg}$ per day.

release curves from matrices without fillers materials until almost $100 \%$ were released. Plots were fitted in the power equation form $\mathrm{M}_{\mathrm{t}} / \mathrm{M}_{\infty}=\mathrm{kx}^{\mathrm{n}}$, where $\mathrm{n}$ is the diffusion exponent, $\mathrm{k}$ is a constant and $\mathrm{M}_{\mathrm{t}} / \mathrm{M}_{\infty}$ is the fractional release of the pheromone component (Table 8).

According to Peppas and Ritger, ${ }^{3}$ for non-swellable controlled release systems spherical samples, the drug release mechanism depends on diffusional exponent $n$, where values of $\mathrm{n}$ lower than 0.43 mean a Fickian diffusion, values $0.43<\mathrm{n}<1.00$ anomalous (non-Fickian) transport and $\mathrm{n}=1.00$ determines a zero-order release. ${ }^{19}$

For sulcatone, we obtained that in paraffin wax mp $70-80{ }^{\circ} \mathrm{C}$, paraffin wax mp $53-57^{\circ} \mathrm{C}$, paraffin oil $(60 \%) /$ paraffin wax mp 53-57 ${ }^{\circ} \mathrm{C}(40 \%)$, stearin and bees wax matrices, pheromone component transport would occur by non Fickian diffusion. However, in carnauba wax and in lanolin wax matrices, Fickian diffusion would be the responsible transport mechanism. In lanolin pentaerythritol 
Table 7. $V_{i}, c$, and $t$ parameters from release curves with their respective standard errors of wax monolithic dispensers for sulcatol

\begin{tabular}{|c|c|c|c|c|}
\hline \multicolumn{5}{|c|}{ Release rate parameters of the curve $\mathrm{m}=\mathrm{ct}^{1 / 2}$ for sulcatol $(20 \% \mathrm{~m} / \mathrm{m})$} \\
\hline Matrix & $\mathrm{c}$ & Standard error ${ }^{\mathrm{a}}$ & $\mathrm{V}_{\mathrm{i}}^{\mathrm{b}} /(\mathrm{mg}$ per day) & $\mathrm{t}^{\mathrm{c}} /$ day \\
\hline Polyethylene glycol 4000 & 3.589 & 1.5744 & 100.3 & 33 \\
\hline Polyethylene glycol $4000+10 \%$ kaolin & 2.668 & 0.9069 & 146.4 & 40 \\
\hline Polyethylene glycol $4000+20 \%$ kaolin & 2.200 & 1.0689 & 213.3 & 40 \\
\hline Polyethylene glycol $4000+30 \%$ kaolin & 2.079 & 1.0751 & 234.3 & 40 \\
\hline Polyethylene glycol $4000+20 \%$ glass spheres & 1.629 & 0.6254 & 270.6 & 31 \\
\hline Polyethylene glycol $4000+20 \%$ molecular sieve & 2.034 & 0.4558 & 192.1 & 26 \\
\hline Polyethylene glycol $4000+20 \%$ activated charcoal & 1.827 & 0.9049 & 291.6 & 40 \\
\hline Polyethylene glycol 6000 & 2.692 & 0.8970 & 127.8 & 54 \\
\hline Polyethylene glycol $6000+10 \%$ kaolin & 2.745 & 0.7716 & 145.7 & 53 \\
\hline Polyethylene glycol $6000+20 \%$ kaolin & 2.409 & 0.8437 & 185.3 & 53 \\
\hline Polyethylene glycol $6000+30 \%$ kaolin & 1.987 & 0.6639 & 275.2 & 53 \\
\hline Polyethylene glycol $6000+20 \%$ glass spheres & 1.348 & 0.7444 & 237.8 & 44 \\
\hline Polyethylene glycol $6000+20 \%$ molecular sieve & 2.096 & 0.5156 & 129.8 & 42 \\
\hline Polyethylene glycol $6000+20 \%$ activated charcoal & 1.885 & 0.5673 & 251.5 & 44 \\
\hline Paraffin mp $53-57^{\circ} \mathrm{C}$ & 2.398 & 0.9796 & 16.7 & 32 \\
\hline Paraffin oil + paraffin mp $53-57^{\circ} \mathrm{C}$ & 1.782 & 0.4966 & 53.5 & 33 \\
\hline Paraffin $\mathrm{mp} 70-80^{\circ} \mathrm{C}$ & 2.947 & 1.2780 & 15.8 & 32 \\
\hline Lanolin wax & 0.913 & 0.3168 & 106.3 & 32 \\
\hline Carnauba wax & 2.507 & 0.5896 & 108.4 & 38 \\
\hline Pentaerythritol ester of lanolin & 2.515 & 0.8669 & 32.0 & 32 \\
\hline Carnauba wax $+10 \%$ kaolin & 2.616 & 0.8609 & 18.6 & 32 \\
\hline Carnauba wax $+20 \%$ kaolin & 2.070 & 0.5694 & 39.8 & 33 \\
\hline Carnauba wax $+30 \%$ kaolin & 3.137 & 1.0290 & 39.4 & 32 \\
\hline Bees wax & 2.700 & 0.9360 & 34.7 & 28 \\
\hline Bees wax $+20 \%$ kaolin & 3.736 & 2.4467 & 35.6 & 27 \\
\hline Bees wax $+20 \%$ Chinese talc & 4.365 & 4.0805 & 36.9 & 30 \\
\hline Stearin & 2.169 & 0.7059 & 9.7 & 18 \\
\hline Stearin $+20 \%$ kaolin & 4.709 & 4.4550 & 21.7 & 47 \\
\hline Stearin $+20 \%$ Chinese talc & 4.280 & 4.3971 & 12.1 & 45 \\
\hline
\end{tabular}

${ }^{a}$ Standard error obtained from SigmaPlot software; ${ }^{b}$ calculated from the differentiation of the pheromone component release curve mass $v s$. time; ${ }^{c}$ time in days until the release rate of the pheromone component was less than $10 \mathrm{mg}$ per day.

Table 8. Calculation of diffusional exponent $\mathrm{n}$ for sulcatone, sulcatol and 3-pentanol from release curves for matrices without fillers (in all cases, $p<0.0001$ )

\begin{tabular}{lccc}
\hline Matrix & $\mathrm{n}$ value for sulcatone \pm SD & $\mathrm{n}$ value for sulcatol \pm SD & $\mathrm{n}$ value for 3-pentanol \pm SD \\
\hline Paraffin wax mp $70-80{ }^{\circ} \mathrm{C}$ & $0.66 \pm 0.009^{\mathrm{a}}$ & $0.79 \pm 0.014^{\mathrm{a}}$ & $0.60 \pm 0.004^{\mathrm{a}}$ \\
Paraffin wax mp $53-57^{\circ} \mathrm{C}$ & $0.63 \pm 0.001^{\mathrm{a}}$ & $0.84 \pm 0.039^{\mathrm{a}}$ & $0.66 \pm 0.017^{\mathrm{a}}$ \\
Paraffin oil $(60 \%)+$ paraffin mp $53-57^{\circ} \mathrm{C}(40 \%)$ & $0.57 \pm 0.045^{\mathrm{a}}$ & $0.72 \pm 0.025^{\mathrm{a}}$ & $0.65 \pm 0.033^{\mathrm{a}}$ \\
Lanolin pentaerythritol ester & $0.44 \pm 0.021^{\mathrm{a}, \mathrm{b}}$ & $0.59 \pm 0.003^{\mathrm{a}}$ & $0.46 \pm 0.014^{\mathrm{a}}$ \\
Sterarin & $0.83 \pm 0.007^{\mathrm{a}}$ & $0.84 \pm 0.001^{\mathrm{a}}$ & $0.84 \pm 0.021^{\mathrm{a}}$ \\
Carnauba wax & $0.39 \pm 0.006^{\mathrm{b}}$ & $0.79 \pm 0.033^{\mathrm{a}}$ & $0.35 \pm 0.033^{\mathrm{b}}$ \\
Bees wax & $0.58 \pm 0.008^{\mathrm{a}}$ & $0.64 \pm 0.007^{\mathrm{a}}$ & $0.60 \pm 0.007^{\mathrm{a}}$ \\
Lanolin wax & $0.39 \pm 0.005^{\mathrm{b}}$ & $0.52 \pm 0.002^{\mathrm{a}}$ & $0.42 \pm 0.009^{\mathrm{b}}$ \\
\hline
\end{tabular}

${ }^{\mathrm{a} A n o m a l o u s ~(n o n-F i c k i a n ~ d i f f u s i o n) ~ t r a n s p o r t ; ~}{ }^{\mathrm{b}}$ Fickian diffusion. SD: standard deviation.

ester the two pheromone transports (Fickian and nonFickian diffusion) mechanisms would be present according to the lower and upper confidence intervals (Table 8). For sulcatol, results showed that non-Fickian diffusion was the responsible mechanism for the pheromone component transport in all matrices (Table 8). For 3-pentanol, we obtained that in paraffin wax mp $70-80{ }^{\circ} \mathrm{C}$, paraffin wax mp 53-57 ${ }^{\circ} \mathrm{C}$, paraffin oil $(60 \%)$ /paraffin wax mp $53-57^{\circ} \mathrm{C}$ 
(40\%), lanolin pentaerythritol ester, stearin and bees wax matrices, the pheromone component transport occurred by non Fickian diffusion; while in monolithic dispensers made of carnauba wax and lanolin wax, Fickian diffusion mechanism would be responsible for the release of 3-pentanol (Table 8).

The non-Fickian diffusion was the predominant mechanism of transport of the three pheromone components. For mating disruption trials, an approximate Fickian diffusion is more desirable in order to obtain relatively constant pheromone concentrations in the air. In these cases where the active ingredient diffuses continuously from the dispenser to the environment, a non-Fickian diffusion would produce a burst of active ingredient in the air that is useful for the case of a toxic insecticide, but is less useful for a pheromone that is expected to be released in a small amount but at constant rate in time.

Quantitative relationships between the physicochemical parameters and pheromone components release rates

Linear and non linear regressions between the pheromone components initial release rates and matrices viscosity or Shore D hardness were evaluated.

For sulcatol, a hyperbolic regression between the matrix viscosities and their initial release rates $V_{i}$, represented by the expression: $V_{i}=a \mu /(b+\mu)$ was found, where $\mu$ is the kinematic viscosity of the matrices and $a$ and $b$ are constants.

Linear regressions between the matrix viscosities and their initial release rates $V_{i}$, represented by the mathematical expression $V_{i}=a \mu+b$ were found for sulcatone and 3 -pentanol. In these equations, $\mathrm{R}^{2}=0.8526$ for sulcatone, and $\mathrm{R}^{2}=0.7651$ for 3-pentanol.

For the three pheromone components, the same type of exponential equation that shows the existing relationships between the matrices hardness and $V_{i}$ represented by $\mathrm{V}_{\mathrm{i}}=\mathrm{ae}^{\mathrm{bD}}$, was found. In this expression, $\mathrm{D}$ is the matrices Shore $\mathrm{D}$ hardness and $\mathrm{a}$ and $\mathrm{b}$ are constants.

Initial release rates increased considerably with the increment of matrices viscosities, bringing out the important effect of viscosity in the pheromone release. ${ }^{18}$ Also, it was noticed that as hardness of matrices increases, release rates of sulcatone, sulcatol and 3-pentanol were higher, and lower release rates were obtained with matrices with lower hardness value. This effect is opposite to that described in other studies, ${ }^{2,20}$ where the increase in stiffness would prevent the reorientation of polymer chains for the diffusion of the component. In this work, harder matrices were more fragile and brittle than softer matrices, and produced cracks in the dispensers that could be responsible for the grater diffusion of pheromone component to the environment.

Some authors obtained different values of release rates, release kinetics, duration time and types of diffusion (Fickian or non Fickian diffusion) with diverse polymeric dispensers formulated for the controlled release of pheromones and got a good performance in the pest management of several insects. For instance, Atterholt et al..$^{21}$ measured pheromone release-rates from paraffin wax and emulsions in laboratory flow cell experiments. Pheromone release from paraffin was partitioned-controlled where the drug being released had a high solubility in the polymeric delivery device and low partition coefficient between the polymer and the surrounding medium, providing a constant (zero-order) release rate. The paraffin's emulsions primarily consisted of $30 \%$ paraffin and $4 \%$ pheromone, and they achieved a constant release rate of the pheromone for more than 100 days at $27^{\circ} \mathrm{C}$, with release rates ranging from 0.4 to $2 \mathrm{mg}$ per day. Shailaja et al. ${ }^{4}$ prepared plasticized (vinyl chloride) dispensers loaded with a fixed concentration of gossyplure pheromone by a solution casting. The dispensers obeyed Fick's law diffusion and released gossyplure at reasonable controlled rate even after 30 days. Cork et al..$^{22}$ developed a polyvinyl chloride-resin-controlled release formulation for pheromones and used it in mating disruption of yellow rice stem borer, Scirpophaga incertulas obtaining a significant reduction in damage. The formulation was ideally suited for the release of 14-carbon acetates and 16-carbon aldehydes with typical field lives of 70-100 days and with half lives of 5.4 and 39.1 at $27^{\circ} \mathrm{C}$ after evaluations in a wind tunnel. They also found that depletion of pheromone components from the polyvinyl chloride-resin formulations was characterized by the exponential equation $\mathrm{y}=\mathrm{ae}^{-\mathrm{bt}}$, where $\mathrm{y}$ is the pheromone percent remaining, $\mathrm{t}$ is the time (days), e is the base natural of logarithms, and $\mathrm{a}$ and $\mathrm{b}$ are constants. Tiboni et $a .^{23}$ used silica porous glass as an insect pheromone dispenser and impregnated this material with different kind of insect's pheromones. They evaluated these silica porous glass dispensers in field obtaining good results, releasing a concentration of active agent of approximately $20 \mu \mathrm{g}$ per day during 20 days. Also, they found that release ratios of pheromones can be optimized for different crop areas, varying the previously impregnated pheromone amount in the dispenser.

\section{Mating disruption field trials}

The selection of the dispensers employed in this field trial was based according to the following properties: relatively high and constant $\mathrm{V}_{\mathrm{i}}$, relatively high $\mathrm{t}$ and high melting 
point of the mixtures of matrices + fillers + pheromones to prevent melting during summer temperatures or washed away by heavy rains. For sulcatol and 3-pentanol, carnauba wax mixed with $30 \% \mathrm{~m} / \mathrm{m}$ of kaolin was selected, and for sulcatone, paraffin mp $70-80{ }^{\circ} \mathrm{C}+30 \% \mathrm{~m} / \mathrm{m}$ kaolin was used. These selected dispensers showed high initial release rates that remained relatively high until $12-15$ days and exhibited the required resistance to heavy rains. Optimal dispensers according to their release rates were selected and deployed in a commercial poplar plantation in Buenos Aires, Argentina during the flight season of M. mutatus. Damage levels before and after treatment in control and treated plots were compared. In control plot, despite field observations that showed a small-scale increase in the damage level measured as MG and AG, no significant differences were observed before and after treatment (MG: $\mathrm{t}=-1.74$; d.f. $($ degrees of freedom $)=13 ; \mathrm{P}=0.1$; AG: $\mathrm{t}=-1.38 ;$ d.f. $=13 ; \mathrm{P}=0.18$ ). However, in both treated plots, a reduction in attack level after pheromone treatment expressed as the mean number of MG (Lot1: $\mathrm{t}=3.22$; d.f. $=13 ; \mathrm{P}=0.006 ;$ Lot $2: \mathrm{t}=2.78 ;$ d.f. $=13 ; \mathrm{P}=0.01$ ) and $\mathrm{AG}$ (Lot1: $\mathrm{t}=2.24 ;$ d.f. $=13 ; \mathrm{P}=0.04 ;$ Lot2: $\mathrm{t}=2.22$; d.f. $=13 ; \mathrm{P}=0.04$ ) was observed (Figures 2 and 3 ).

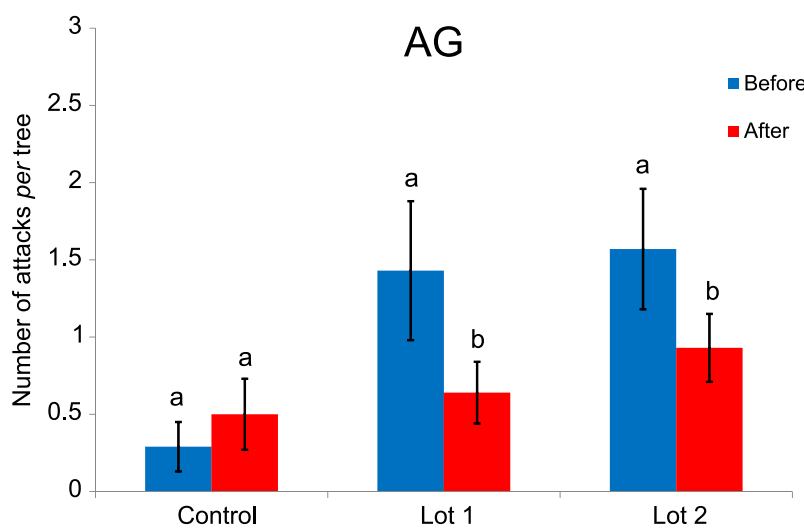

Figure 2. Results of field trials expressed in active galleries (AG) damage before and after pheromone treatment with monolithic dispensers. Means followed by the same letter are not significantly different $(\alpha=0.05)$.

After the experiment, the number of mating and active galleries was slightly increased in control plots and decreased in treated plots. These results confirmed the previous findings with polymeric dispensers of zero order kinetics ${ }^{9}$ that the strategy of mating disruption using the pheromone delivery doses is a feasible tool for management of infested poplar plantations.

The population level of the beetle affects the success of mating disruption. ${ }^{24}$ In the present work, the initial density was 1-2 attacks per tree, which is low, and reductions of damage levels of $40 \%$ were obtained. Also, in the treatment of several lepidopteran insects the efficacy of different types

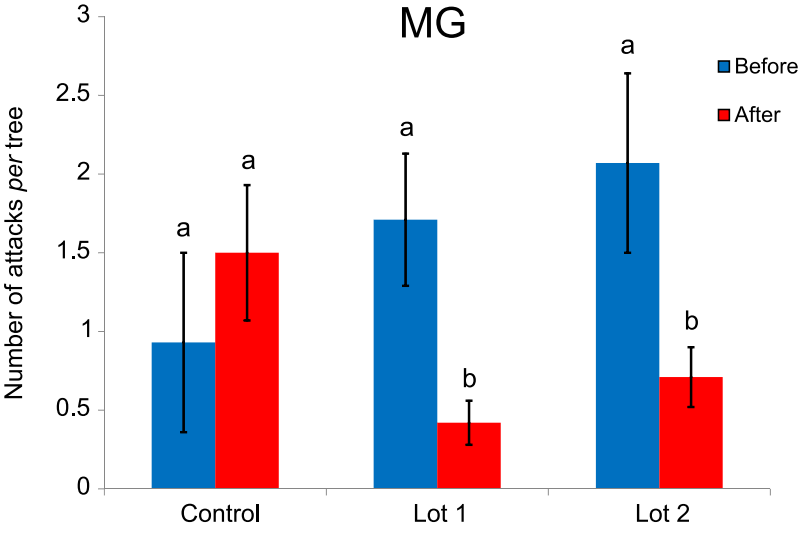

Figure 3. Results of field trials expressed in mating galleries (MG) damage before and after pheromone treatment with monolithic dispensers. Means followed by the same letter are not significantly different $(\alpha=0.05)$.

of formulations with pheromones was highly dependent on insect population density. ${ }^{25-28}$

Synthetic pheromones of $M$. mutatus are not expensive to produce but the application process is labor intensive. Also, it is critical to have an effective monitoring schedule to detect the beginning of the flying period with pheromonebaited traps in order to maximize the benefit-cost ratio of the control treatment. Overall, the costs of mating disruption treatments are affordable considering the increasing market prices of poplar timber in Argentina, where damage affects commercially important poplar and hazelnut plantations.

\section{Conclusions}

In the solid monolithic dispensers developed in this work, matrix hardness and viscosity, and fillers particle size were mostly responsible for the varied patterns in pheromone component release curves, showing different initial release rates according to different affinities between the molecules and the matrices.

Variation in the parameters values of $\mathrm{V}_{\mathrm{i}}, \mathrm{t}$ and diffusion in monolithic dispensers in accordance to the pheromone component and the type of matrix depend on the degree on how the pheromone component molecule is attached or bonded to the matrix surface.

The physicochemical parameters that influence the release of pheromone components from the half-sphere shaped wax monolithic dispensers can be modulated as required by the geographical and/or meteorological conditions of the field, as well as according to the insect biology or the purpose of the field trial.

Efficient controlled-release systems are essential to deliver behaviorally relevant aerial concentrations of sex pheromones for both monitoring and mating disruption purposes in the field. The use of natural materials for dispensers has many advantages from an environmental 
perspective and also, dispensers deployed in the field do not require additional work to ultimately dispose them after the treatment.

\section{Supplementary Information}

Supplementary information with pictures of the dispensers, the assemblage of experiments in the field and the damages caused by $M$. mutatus is available free of charge at http://jbcs.sbq.org.br as PDF file.

\section{Acknowledgments}

This work was supported by the Agencia Nacional de Promoción Científica y Técnica (PICT 2010-305), MinAgri (SAFO I-103) and CONICET (Argentina).

\section{References}

1. Kydonieus, A. F.; Beroza, M.; Insect Suppression with Controlled Release Pheromone Systems, $1^{\text {st }}$ ed.; CRC Press: Boca Raton, USA, 1982, ch. 3.

2. Kydonieus, A. F.; Controlled Release Technologies: Methods, Theory, and Applications, $1^{\text {st }}$ ed.; Kydonieus, A. F., ed.; CRC Press: Boca Raton, USA, 1980, ch. 2.

3. Ritger, P. L.; Peppas, N. A.; J. Controlled Release 1987, 5, 23.

4. Shailaja, D.; Merajuddin, A. S.; Yassen, M.; J. Appl. Polym. Sci. 1997, 64, 1373.

5. Heuskin, S.; Verheggen, F. J.; Haubruge, E.; Wathelet, J.; Lognay, G.; Biotechnol., Agron., Soc. Environ. 2011, 15, 459.

6. Stipanovic, A. J.; Henessy, P. J.; Webster, F. X.; Takahashi, Y.; J. Agric. Food Chem. 2004, 52, 2301.

7. Gatti Liguori, P.; Zerba, E.; Alzogaray, R.; González Audino, P.; J. Chem. Ecol. 2008, 34, 1446.

8. Girardi, G. S.; Giménez, R. A.; Braga, M. R.; Neotrop. Entomol. 2006, 35, 864.

9. Funes, H.; Griffo, R.; Zerba, E.; González Audino, P.; Entomol. Exp. Appl. 2011, 139, 226.

10. Tojo, K.; J. Pharm. Sci. 1985, 74, 685.

11. Funes, H.; Zerba, E.; González Audino, P.; Agric. Forest Entomol. 2015, 18, 52.
12. ASTM D445: Standard Test Method for Kinematic Viscosity of Transparent and Opaque Liquids (and Calculation of Dynamic Viscosity; American Society for Testing and Materials: West Conshohocken, USA, 2006.

13. ASTM D2240-05: Standard Test Method for Rubber PropertyDurometer Hardness; American Society for Testing and Materials: West Conshohocken, USA, 2010.

14. Santoro, F. H.; Rev. Invest. For. 1962, 3, 25.

15. Santoro, F. H.; Rev. Invest. For. 1963, 4, 47.

16. Harris, J. M.; Poly (Ethylene Glycol) Chemistry, Biotechnical and Biomedical Applications, $1^{\text {st }}$ ed.; Harris, J. M., ed.; Plenum Press: New York, USA, 1992, ch.1.

17. Kerton, F.; Marriott, R.; Alternative Solvents for Green Chemistry, $2^{\text {nd }}$ ed.; The Royal Society of Chemistry: Cambridge, United Kingdom, 2013.

18. Kung, H. Y.; Effects of Molecular Weight, Polydispersity and Solution Viscosity of Cellulose Acetate Butyrate on Properties and Release Characteristics of Ascorbyl Palmitate Microcapsules; University of Rhode Island: Kingston, 1997, p. 78.

19. De Kee, D.; Liu, Q.; Hinestroza, J.; Can J. Chem. Eng. 2005, 83,913

20. Akelah, A.; Functionalized Polymeric Materials in Agriculture and the Food Industry; Springer: New York, USA, 2013, ch. 1.

21. Atterholt, C. A.; Delwiche, M. J.; Rice, R. E.; Krochta, J. M.; J. Controlled Release 1998, 57, 233.

22. Cork, A.; de Souza, D. R.; Hall, O. T.; Jones, E.; Casagrande, E.; Krishnaiah, K.; Syed, Z.; Crop Prot. 2008, 27, 248.

23. Tiboni, A.; Coracini, M. D. A.; Lima, E. R.; Zarbin, P. H. G.; Zarbin, A.; J. Braz. Chem. Soc. 2008, 19, 1634.

24. Howell, J. F.; Knight, A. L.; Unruh, T. R.; Brown, D. F.; Krysan, J. L.; Sell, C. R.; Kirsch, P. A.; J. Econ. Entomol. 1992, 58, 918.

25. Stelinski, L. L.; Mc Ghee, P.; Grieshop, M.; Brunner, J.; Gut, L. J.; Agr. Forest Entomol. 2008, 10, 389.

26. Vickers, R. A.; Rothschild, G. H. L.; Tortricid Pest: Their Biology, Natural Enemies and Control, $1^{\text {st }}$ ed.; van der Geest, L. P. S.; Evenhuis, H. H., eds.; Elsevier: New York, USA, 1991.

27. Trimble, R. M.; Can. Entomol. 1995, 127, 493.

28. Schmitz, V.; Roehrich, R.; Stockel, J.; J. Appl. Entomol. 1995, 199, 303. 